\title{
Protective effects of osthole against myocardial ischemia/reperfusion injury in rats
}

\author{
XIAN-YUE WANG ${ }^{1 *}$, WEN-PENG DONG ${ }^{1 *}$, SHENG-HUI BI $^{1 *}$, ZHI-GUO PAN $^{2 *}$, HAO YU $^{1}$, \\ XIAO-WU WANG ${ }^{1}$, TAO MA ${ }^{1}$, JUN WANG ${ }^{1}$ and WEI-DA ZHANG ${ }^{1}$ \\ ${ }^{1}$ Department of Cardiovascular Surgery, ${ }^{2}$ Intensive Care Unit, Guangzhou General Hospital \\ of Guangzhou Military Command, Guangzhou, Guangdong 510010, P.R. China
}

Received March 5, 2013; Accepted May 10, 2013

DOI: $10.3892 / \mathrm{ijmm} .2013 .1386$

\begin{abstract}
Osthole, a bioactive simple coumarin derivative extracted from a number of medicinal plants, such as Cnidium monnieri and Angelica pubescens, has been shown to exert a variety of pharmacological activities and is considered to have potential therapeutic applications. In this study, we investigated the protective effects of osthole against myocardial ischemia/ reperfusion (I/R) injury in rats. Male Sprague-Dawley rats were randomly assigned to 1 of 5 groups: the sham-oeprated control group (control), the vehicle group (vehicle), and 3 treatment groups, which were treated with osthole at the concentration of 1,10 or $50 \mathrm{mg} / \mathrm{kg}$ (intraperitoneally), respectively, upon the initiation of myocardial ischemia. Treatment with osthole suppressed the formation of lipid peroxidation products, enhanced the capacities of antioxidant enzymes and inhibited the expression of inflammatory cytokines following myocardial I/R injury. Moreover, treatment with osthole reduced highmobility group box protein 1 (HMGB1) and phosphorylated nuclear factor $(\mathrm{NF})-\kappa \mathrm{B}$ expression in ischemic myocardial tissue. These results demonstrate the protective effects of osthole against myocardial I/R injury in rats and suggest that these effects may be associated with its antioxidant and antiinflammatory activities.
\end{abstract}

\section{Introduction}

Cardiovascular diseases, such as atherosclerotic coronary heart disease, congestive heart failure, hypertensive heart disease

Correspondence to: Dr Wei-da Zhang, Department of Cardiovascular Surgery, Guangzhou General Hospital of Guangzhou Military Command, Guangzong Street, Guangzhou, Guangdong 510010, P.R. China

E-mail: guangzongzhangwd@163.com

${ }^{*}$ Contributed equally

Key words: osthole, anti-inflammation, cardioprotection, ischemia/ reperfusion and stroke, are still major health issues worldwide, particularly in advanced countries (1). According to the American Heart Association (AHA), ischemic heart disease was the single leading cause of death in adults in the US, with the estimated direct and indirect costs of $>177.1$ billion dollars for the year 2010 (2). However, pharmacological therapies aimed to reduce symptoms have multiple systemic side-effects, and do not effectively halt the pathophysiological progression associated with ischemic heart disease $(3,4)$. Additionally, intervention or surgical revascularization procedures in patients with stenotic lesion-induced ischemic heart disease do not provide long-term relief, and frequently, patients require repeat revascularization procedures within a few years (5). Therefore, the development of pharmacological agents effective against this condition is mandatory.

Over the years, several pharmacological compounds and agents have been shown to have cardioprotective effects in animal experiments; however, only a few of these have been successfully translated to the clinic (6). This may be due, not only to possible inter-species differences in drug efficacy, but also to multiple systemic side-effects, as well as the limited therapeutic time window (7). Studies have found that many natural products (particularly herbal medicines) provide an ideal source for the development of safe and effective agents for the treatment of ischemic heart disease $(8,9)$. Osthole (7-methoxy-8-isopentenoxycoumarin), a plant coumarin compound, is an active constituent isolated from a number of plants, such as Cnidium monnieri and Angelica pubescens. In traditional Chinese medicine, these plants have been used as tonics and aphrodisiacs, and have been administered to humans in clinical practice for several years (10). Modern pharmacological studies have shown that osthole possesses a variety of pharmacological and biological activities, such as anti-hepatic (11), anti-inflammatory $(12)$, antitumor $(13,14)$, anti-apoptotic (15), as well as anti-allergic and estrogen-like effects $(16,17)$. It is considered to have potential therapeutic applications, and previous studies have shown that osthole protects against cerebral ischemic reperfusion injury in vitro and in vivo $(18,19)$. In the present study, we investigated the potential protective effects of osthole against myocardial ischemia reperfusion (I/R) injury, as well as its mechanisms of action, focusing on its anti-inflammatory and antioxidant activities. 


\section{Materials and methods}

Animals. Male Sprague-Dawley rats weighing 350-450 g were housed at $20-22^{\circ} \mathrm{C}$ with a 12 -h light/dark cycle. Standard animal chow and water were freely available. All experimental protocols were approved by the Institutional Animal Care and Use Committee of the Fourth Military Medical University and were performed in accordance with the NIH Guide for the Care and Use of Laboratory Animals (NIH publication no. 80-23, revised 1996). All efforts were made to minimize the number of animals used, as well as their suffering.

Myocardial I/R injury. Coronary occlusion and reperfusion were performed as previously described (20). The rats were anesthetized and the arterial blood $\mathrm{pH}$ and gases were maintained within normal physiological limits by a rodent respirator. After the chest was opened by a middle thoracotomy, a 4-0 black silk ligature was placed under the left anterior descending (LAD) coronary artery, and the ends of the tie were threaded through a small vinyl tube to form a snare for reversible LAD coronary artery occlusion. In the vehicle- and osthole-treated animals, myocardial ischemia was induced by tightening the snare with a clip for $30 \mathrm{~min}$, and reperfusion was established by loosening the snare. The ligature was placed under the LAD coronary artery without occlusion in the control animals.

Drug preparation and experimental protocol. Osthole (>98\% purity) was purchased from the National Institute for the Control of Pharmaceutical and Biological Products (Beijing, China) and dissolved in dimethyl sulfoxide (DMSO) $(<0.1 \%$, which had no toxicity). All animals were randomly assigned to 1 of 5 groups: the control group (control), the vehicle group (vehicle), and 3 treatment groups, which were treated with osthole at the concentration of 1,10 or $50 \mathrm{mg} / \mathrm{kg}$ (intraperitoneally), respectively, upon the initiation of myocardial ischemia. The control group was only subjected to surgical procedures (sham-operated), while the other animals were subjected to myocardial ischemia and reperfusion 30 min later. In addition, the control group and the vehicle group were intraperitoneally administered an equal volume of the solution used to dissolve osthole at the same time.

Hemodynamic assessment. The right common carotid artery was exposed and cannulated with a $2 \mathrm{~F}$ Millar Catheter into the left ventricle through the ascending aorta to monitor heart function, including left ventricular systolic pressure (LVSP), left ventricular end-diastolic pressure (LVEDP), heart rate (HR), mean arterial pressure (MAP) and first derivative $( \pm d p /$ $\left.d t_{\text {max }}\right)$ of left ventricular pressure in each group. To eliminate the confounding factor in which the loading conditions of the heart may influence cardiovascular parameters, additional rats were used to examine whether osthole on its own has an effect on LVSP, LVEDP, HR and $\pm d p / d t_{\max }$ in normal hearts under sham-operated conditions.

Analysis of myocardial infarction. Myocardial infarction was determined according to a previously described method (21). Briefly, $2 \mathrm{ml}$ of $1 \%$ Evans blue dye was injected into the femoral vein to distinguish between the perfused and nonperfused [area at risk (AAR)] sections of the heart following
$24 \mathrm{~h}$ of reperfusion. The AAR was cut into small sections and incubated with a $1 \%$ solution of 2,3,5-triphenyltetrazolium chloride (TTC) for $30 \mathrm{~min}$ at $37^{\circ} \mathrm{C}$ followed by fixation in a $4 \%$ paraformaldehyde solution to visualize the infarct area. Infarct size was expressed as the percentage of the ischemic area (IA) in each heart.

Lactate dehydrogenase ( $L D H)$ estimation. The animal hearts were removed from liquid nitrogen, weighed and a $10 \%$ homogenate was prepared in iced phosphate buffer. The homogenate was then cold centrifuged at 5,000 rpm for $20 \mathrm{~min}$ and the supernatant was used for the estimation of LDH levels using commercialized assay kits according to the manufacturer's instructions (Nanjing Jiancheng Bioengineering Institute, Nanjing, China). One unit of LDH is defined as the amount of enzyme required to reduce $1 \mu \mathrm{mol}$ of pyruvate to $\mathrm{D}$-lactate/min at $\mathrm{pH} 7$ and $25^{\circ} \mathrm{C}$. $\mathrm{LDH}$ levels are expressed as IU/mg protein.

Creatine kinase-MB (CK-MB) isoenzyme estimation. CK-MB isoenzyme levels were estimated using a commercial kit from Santa Cruz Biotechnology, Inc. (Santa Cruz, CA,USA) according to the manufacturer's instructions. Briefly, $50 \mu \mathrm{l}$ of each sample were added to tubes containing $1 \mathrm{ml}$ of imidazole buffer consisting of adenosine monophosphate (AMP, $5.2 \mathrm{mM}$ ), adenosine diphosphate (ADP, $2.1 \mathrm{mM}$ ), nicotinamide adenine dinucleotide phosphate (NADPH, $2.1 \mathrm{mM}$ ), glucose6-phosphate dehydrogenase (G6PD, $1.6 \mathrm{U} / \mathrm{l})$, phosphocreatine $(\mathrm{CP}, 31.2 \mathrm{mM})$ and $\mathrm{N}$-acetylcysteine $(\mathrm{NAC}, 21 \mathrm{mM})$. The cubes consisting of samples and imidazole buffer were incubated for $2 \mathrm{~min}$ at room temperature. Absorbance was recorded at $340 \mathrm{~nm}$ for $180 \mathrm{sec}$ at $60 \mathrm{sec}$ intervals. One unit of CK-MB isoenzyme is defined as the amount of enzyme that will transfer $1 \mu \mathrm{mol}$ of phosphate from $\mathrm{CP}$ to $\mathrm{ADP} / \mathrm{min}$ at $\mathrm{pH} 7.4$ and $30^{\circ} \mathrm{C}$. The absorbance of the reaction mixture was measured at $340 \mathrm{~nm}$ for $3 \mathrm{~min}$ every $60 \mathrm{sec}$. CK-MB levels are expressed as IU/mg protein.

Biochemical analyses. The rats were sacrificed and the heart tissue samples were obtained for the measurement of lipid peroxidation parameters and antioxidant enzyme activities. The homogenate was centrifuged and the supernatant was used for the assays of malonyldialdehyde (MDA) and 4-hydroxynonenal (4-HNE) levels by colorimetric analysis using a spectrophotometer with the associated detection kits (Cayman Chemical Co., Ann Arbor, MI, USA). The activities of superoxide dismutase (SOD), glutathione peroxidase (GPx) and catalase (CAT) were also measured according to the manufacturer's instructions (Nanjing Jiancheng Bioengineering Institute). In brief, SOD activity was determined by luciferase chemiluminescence elicited by the xanthine oxidase system; GPx activity was assayed by the oxidization of glutathione based on the development of a yellow color with 5,50-dithiobis-(2-nitrobenzoic acid) (DTNB); CAT activity was determined by the absorbance of the remaining $\mathrm{H}_{2} \mathrm{O}_{2}$ using a colorimetric method.

Enzyme-linked immunosorbent assay (ELISA). Twenty-four hours following the induction of myocardial I/R, blood samples were collected and frozen below $-70^{\circ} \mathrm{C}$ until analysis. Serum levels of the inflammatory cytokines, tumor necrosis factor (TNF)- $\alpha$ and interleukin (IL)-6, as well as those of the 


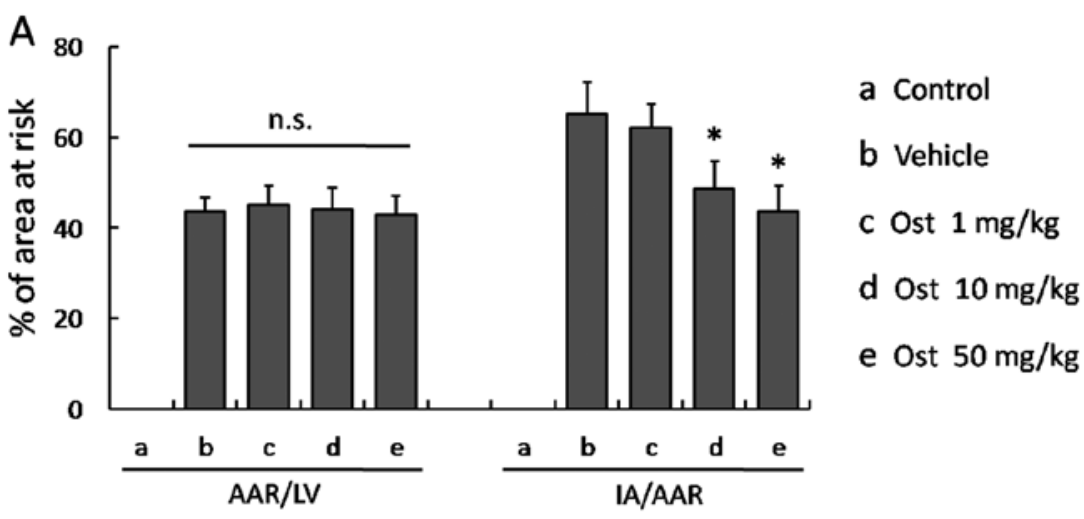

B

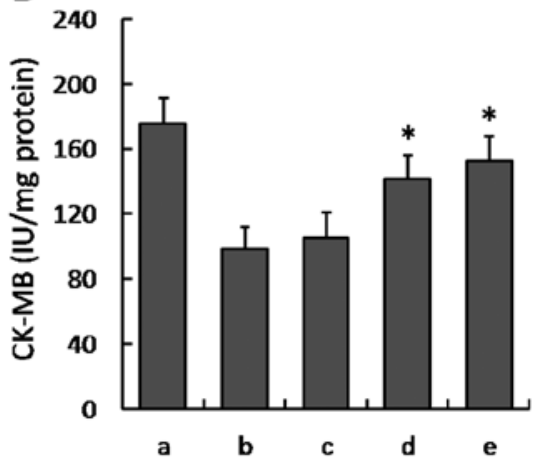

C

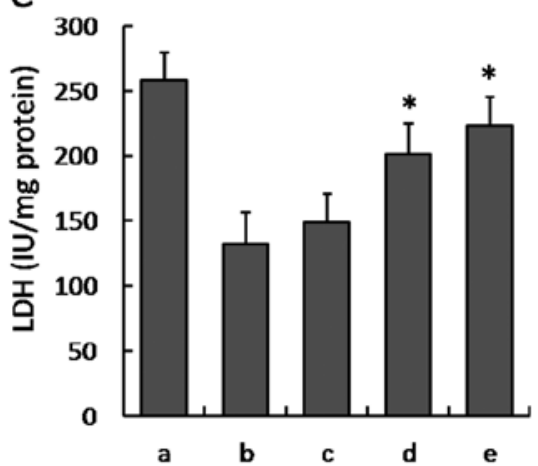

Figure 1. Osthole reduces myocardial damage following ischemia/reperfusion (I/R) injury. The rats were treated with dimethyl sulfoxide (DMSO) solution (vehicle) or osthole at different concentrations $(1,10$ or $50 \mathrm{mg} / \mathrm{kg}$ ) upon the initiation of myocardial I/R. (A) Myocardial infarct volume and the activities of (B) creatine kinase-MB (CK-MB) and (C) lactate dehydrogenase (LDH) in the heart tissues were assayed $24 \mathrm{~h}$ following reperfusion. The data are presented as the means \pm SD from 6 experiments. ${ }^{*} \mathrm{P}<0.05$ vs. vehicle group. n.s., not significant; AAR, area at risk; LV, left ventricle; IA, ischemic area.

myocardial protective cytokine, IL-10, were measured using ELISA kits according to manufacturer's instructions.

Western blot analysis. The protein concentration was determined using a BCA protein assay kit. Equivalent amounts of protein (40 $\mu \mathrm{g} /$ lane) were loaded and separated by $10 \%$ SDS-PAGE gels, and transferred onto polyvinylidene difluoride (PVDF) membranes. The membranes were blocked with $5 \%$ non-fat milk solution in Tris-buffered saline with $0.1 \%$ Triton X-100 (TBST) for $1 \mathrm{~h}$, and then incubated overnight at $4^{\circ} \mathrm{C}$ with primary phosphorylated I $\mathrm{B}-\alpha$ antibody (1:600), phosphorylated nuclear factor (NF)- $\kappa$ B antibody (1:600), highmobility group box protein 1 (HMGB1) antibody $(1: 1,000)$ or $\beta$-actin antibody (1:800) dilutions in TBST. Subsequently, the membranes were washed and incubated with a secondary antibody for $1 \mathrm{~h}$ at room temperature. Image J software was then used to quantify the optical density of each band.

Statistical analysis. Statistical analysis was performed using SPSS 16.0, a statistical software package. Statistical evaluation of the data was performed by one-way analysis of variance (ANOVA). A value of $\mathrm{P}<0.05$ was considered to indicate a statistically significant difference.

\section{Results}

Osthole reduces myocardial damage following $I / R$ injury. To investigate the potential protective effects of osthole against myocardial I/R injury, we first measured the myocardial infract volume. The IA at risk (ARR/LV) induced by coronary occlusion did not differ between the vehicle- and ostholetreated groups (Fig. 1A). The administration of osthole induced a statistically significant reduction in IA/AAR values as compared with the vehicle group in a dose-dependent manner, although $1 \mathrm{mg} / \mathrm{kg}$ osthole was not effective compared with the vehicle group $(\mathrm{P}>0.05)$. We then assayed the level of the myocyte injury marker enzymes, CK-MB and LDH, in the heart tissues challenged with I/R insults. Osthole significantly prevented the depletion of myocyte marker enzymes induced by myocardial I/R injury as evidenced by the significant restoration of CK-MB isoenzyme and $\mathrm{LDH}$ enzyme levels in comparison with the vehicle group.

Osthole improves functional recovery following I/R injury. The hemodynamic changes recorded in the anesthetized animals are presented in Table I. Following myocardial I/R injury, LVEDP was significantly increased, while LVSP and $\pm d p /$ $d t_{\max }$ were decreased in the vehicle-treated rats as compared with the control rats; these effects were all partly reversed following treatment with osthole (10 and $50 \mathrm{mg} / \mathrm{kg}$ ). Moreover, no significant difference in LVEDP, LVSP, HR and $\pm d p / d t_{\max }$ was observed between the normal control rats treated with the vehicle or osthole under sham-operated conditions (Table II).

Effects of osthole on lipid peroxidation following I/R injury. To determine the effects of osthole on lipid peroxidation, heart 
Table I. Hemodynamic measurements following myocardial I/R injury.

\begin{tabular}{lcccccc}
\hline & LVSP $(\mathrm{mmHg})$ & LVEDP $(\mathrm{mmHg})$ & $+d p / d t_{\max }$ & $-d p / d t_{\max }$ & HR $(\mathrm{bpm})$ & MAP $(\mathrm{mmHg})$ \\
\hline Control & $106 \pm 8$ & $8.8 \pm 1.7$ & $9038 \pm 812$ & $8426 \pm 730$ & $323 \pm 23$ & $81 \pm 6$ \\
Vehicle & $62 \pm 7^{\mathrm{a}}$ & $12.3 \pm 2.3^{\mathrm{a}}$ & $5653 \pm 612^{\mathrm{a}}$ & $5153 \pm 608^{\mathrm{a}}$ & $353 \pm 17$ & $74 \pm 8$ \\
Ost $1 \mathrm{mg} / \mathrm{kg}$ & $73 \pm 9$ & $11.6 \pm 1.3$ & $6245 \pm 533$ & $5852 \pm 742$ & $328 \pm 27$ & $78 \pm 7$ \\
Ost $10 \mathrm{mg} / \mathrm{kg}$ & $83 \pm 8^{\mathrm{b}}$ & $10.4 \pm 1.9^{\mathrm{b}}$ & $7547 \pm 712^{\mathrm{b}}$ & $6843 \pm 603^{\mathrm{b}}$ & $365 \pm 22$ & $69 \pm 8$ \\
Ost $50 \mathrm{mg} / \mathrm{kg}$ & $89 \pm 8^{\mathrm{b}}$ & $9.5 \pm 1.1^{\mathrm{b}}$ & $8116 \pm 594^{\mathrm{b}}$ & $7335 \pm 665^{\mathrm{b}}$ & $346 \pm 32$ & $77 \pm 9$ \\
\hline
\end{tabular}

Animals were treated with osthole (Ost; 1,10 or $50 \mathrm{mg} / \mathrm{kg}$ ) or the vehicle $(0.1 \%$ DMSO) upon the initiation of myocardial $\mathrm{I} / \mathrm{R}$ injury, and hemodynamic parameters were measured. Data are presented as the means $\pm \mathrm{SD}$. ${ }^{\mathrm{a}} \mathrm{P}<0.05$ vs. control group. ${ }^{\mathrm{b}} \mathrm{P}<0.05$ vs. vehicle group. I/R, ischemia/reperfusion; LVSP, left ventricular systolic pressure; LVEDP, left ventricular end-diastolic pressure; $+d p / d t_{\max }$, indice of left ventricular contraction; - $d p / d t_{\max }$, indice of left ventricular relaxation; HR, heart rate; MAP, mean arterial pressure; DMSO, dimethyl sulfoxide.

Table II. Time course of hemodynamic changes in normal control rats treated with osthole (50 mg/kg) or the vehicle (0.1\% DMSO).

\begin{tabular}{|c|c|c|c|c|c|c|c|c|c|c|}
\hline \multirow[b]{2}{*}{ Time (h) } & \multicolumn{5}{|c|}{ Osthole (50 mg/kg, n=5) } & \multicolumn{5}{|c|}{ Vehicle $(0.1 \%$ DMSO $0.25 \mathrm{ml}, \mathrm{n}=5)$} \\
\hline & $\begin{array}{c}\text { LVSP } \\
(\mathrm{mmHg})\end{array}$ & $\begin{array}{l}\text { LVEDP } \\
(\mathrm{mmHg})\end{array}$ & $+d p / d t_{\max }$ & $-d p / d t_{\max }$ & $\begin{array}{l}\text { HR } \\
\text { (bpm) }\end{array}$ & $\begin{array}{c}\text { LVSP } \\
(\mathrm{mmHg})\end{array}$ & $\begin{array}{l}\text { LVEDP } \\
(\mathrm{mmHg})\end{array}$ & $+d p / d t_{\max }$ & $-d p / d t_{\max }$ & $\begin{array}{c}\mathrm{HR} \\
(\mathrm{bpm})\end{array}$ \\
\hline 0 & $110 \pm 7$ & $9.7 \pm 2.1$ & $10521 \pm 747$ & $9567 \pm 614$ & $225 \pm 16$ & $115 \pm 8$ & $10.4 \pm 2.3$ & $10244 \pm 818$ & $9166 \pm 603$ & $233 \pm 14$ \\
\hline 0.5 & $97 \pm 6$ & $10.8 \pm 3.5$ & $10123 \pm 812$ & $9192 \pm 523$ & $231 \pm 22$ & $107 \pm 7$ & $11.2 \pm 3.5$ & $9875 \pm 653$ & $9250 \pm 750$ & $241 \pm 18$ \\
\hline 1 & $112 \pm 9$ & $11.8 \pm 2.6$ & $9834 \pm 653$ & $8961 \pm 496$ & $245 \pm 19$ & $104 \pm 9$ & $12.1 \pm 2.7$ & $10144 \pm 752$ & $8783 \pm 565$ & $252 \pm 21$ \\
\hline 2 & $101 \pm 8$ & $11.5 \pm 4.1$ & $9699 \pm 712$ & $8732 \pm 568$ & $233 \pm 17$ & $96 \pm 8$ & $13.3 \pm 3.2$ & $9793 \pm 703$ & $8821 \pm 784$ & $246 \pm 19$ \\
\hline
\end{tabular}

Animals were treated with osthole $(50 \mathrm{mg} / \mathrm{kg})$ or the vehicle $(0.1 \% \mathrm{DMSO})$, and hemodynamic parameters were measured at $0,0.5,1$ and $2 \mathrm{~h} \mathrm{later}$. Data are presented as the means \pm SD. No significant differences were detected between any of the different groups. DMSO, dimethyl sulfoxide; LVSP, left ventricular systolic pressure; LVEDP, left ventricular end-diastolic pressure; $+d p / d t_{\max }$, indice of left ventricular contraction; $-d p / d t_{\max }$, indice of left ventricular relaxation; HR, heart rate.

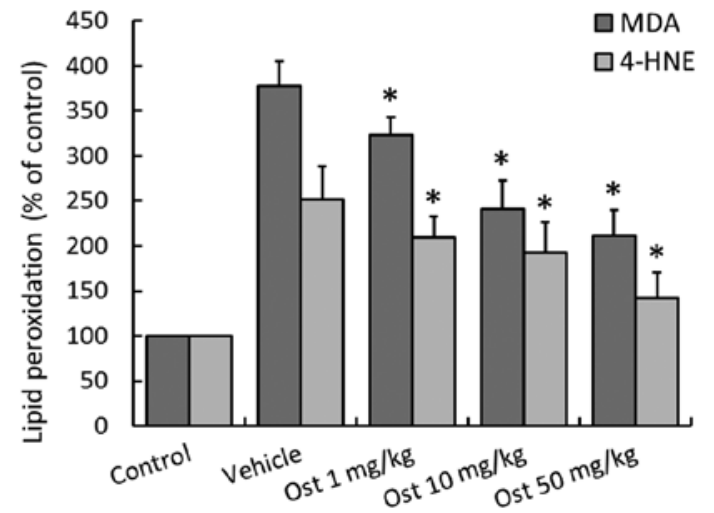

Figure 2. Osthole (Ost) inhibits lipid peroxidation following myocardial ischemia/reperfusion (I/R) injury. The rats were treated with dimethyl sulfoxide (DMSO) solution (vehicle) or osthole at different concentrations $(1,10$ or $50 \mathrm{mg} / \mathrm{kg}$ ) upon the initiation of myocardial I/R, and the content of malonyldialdehyde (MDA) and 4-hydroxynonenal (4-HNE) in the heart tissues was measured $24 \mathrm{~h}$ later. The data are presented as the means \pm SD from 6 experiments. " $\mathrm{P}<0.05$ vs. vehicle group.

tissue samples were obtained $24 \mathrm{~h}$ following myocardial I/R injury. Myocardial I/R injury induced a significant increase in lipid peroxidation, as reflected by the increased levels of MDA and 4-HNE (to $378 \pm 20$ and $252 \pm 24 \%$ of the control levels, respectively) (Fig. 2). A reduction in MDA and 4-HNE forma- tion was observed in the osthole-treated rats as compared with the vehicle-treated animals, indicating that osthole prevents lipid peroxidation induced by myocardial I/R injury.

Effects of osthole on antioxidant enzyme activity following $I / R$ injury. Concomitant to the increased MDA and 4-HNE formation, a significant decrease in the activities of the antioxidant enzymes, SOD, GPx and CAT, was observed in the vehicle group in comparison with the control group at 4 and $24 \mathrm{~h}$ following myocardial I/R injury, demonstrating the damage to the endogenous antioxidant system induced by myocardial I/R injury (Fig. 3). Treatment with osthole significantly preserved the enzyme activity of SOD, GPx and CAT at 4 and $24 \mathrm{~h}$ following myocardial I/R injury in a dose-dependent manner, although $1 \mathrm{mg} / \mathrm{kg}$ osthole was not effective at $4 \mathrm{~h}$ when compared with the vehicle-treated rats $(\mathrm{P}>0.05)$.

Effects of osthole on the expression of inflammatory cytokines. To investigate the potential anti-inflammatory activity of osthole following myocardial I/R injury, the levels of cytokines associated with inflammation, such as TNF- $\alpha$, IL-6 and IL-10 were measured in the blood samples using ELISA. Osthole (10 and $50 \mathrm{mg} / \mathrm{kg}$ ) markedly decreased the expression of TNF- $\alpha$ as compared with the vehicle group, and a similar pattern was observed in the IL-6 concentration (Fig. 4A and B). 
A

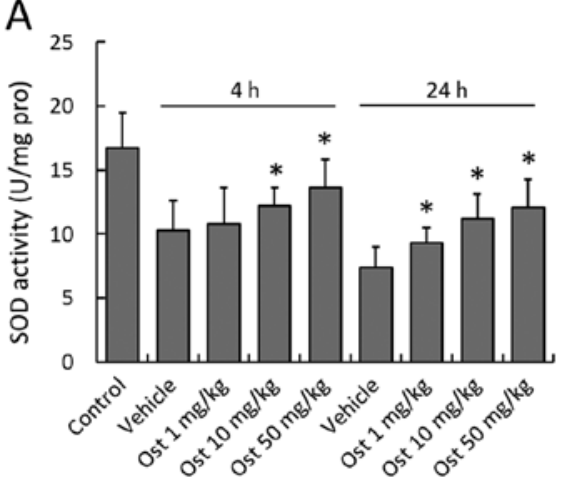

B

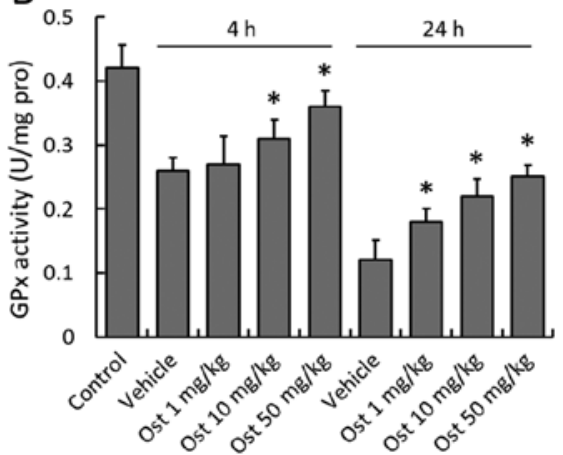

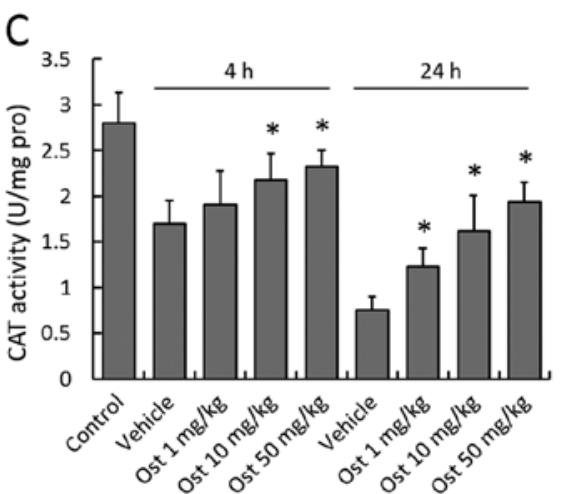

Figure 3. Osthole (Ost) increases antioxidant enzymes activities after ischemia/reperfusion (I/R) injury. The rats were treated with dimethyl sulfoxide (DMSO) solution (Vehicle) or osthole at different concentrations (1, 10 or $50 \mathrm{mg} / \mathrm{kg}$ ) upon the initiation of myocardial I/R injury. The activities of (A) superoxide dismutase (SOD), (B) glutathione peroxidase (GPx) and (C) catalase (CAT) were measured at 4 and 24 h after the initiation of myocardial I/R injury. The data are presented as the means \pm SD from 6 experiments. ${ }^{*} \mathrm{P}<0.05$ vs. vehicle group.
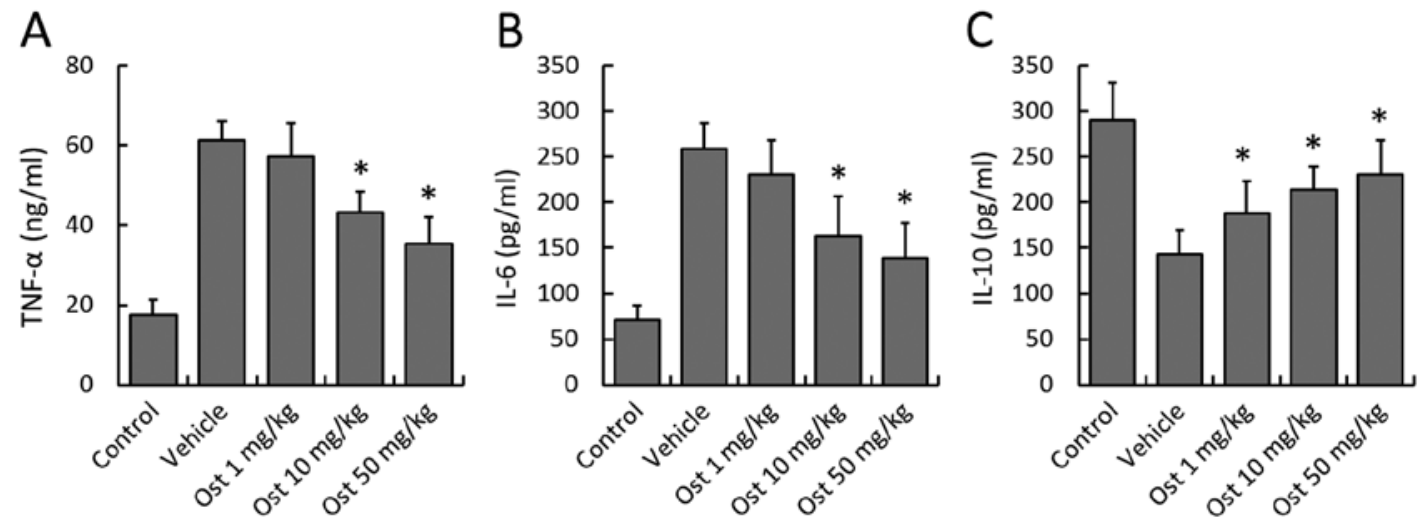

Figure 4. Osthole (Ost) attenuates the expression of inflammatory cytokines following myocardial ischemia/reperfusion (I/R) injury. The rats were treated with dimethyl sulfoxide (DMSO) solution (vehicle) or osthole at different concentrations (1, $10 \mathrm{or} 50 \mathrm{mg} / \mathrm{kg}$ ) upon the initiation of myocardial I/R, and the expression of the inflammatory cytokines, (A) tumor necrosis factor (TNF)- $\alpha$, (B) interleukin (IL)-6 and (C) IL-10, was assayed by ELISA $24 \mathrm{~h}$ later. The data are presented as the means $\pm \mathrm{SD}$ from 6 experiments. $\mathrm{P}<0.05$ vs. vehicle group.

By contrast, the concentration of IL-10, an anti-inflammatory cytokine, was significantly higher in the osthole-treated groups compared with the vehicle group (Fig. 4C).

Effects of osthole on the activities of $I \kappa B-\alpha$ and $N F-\kappa B$, and $H M G B 1$ expression. To further shed light on the potential molecular mechanisms behind the cardioprotective effects of osthole, the expression levels of HMGB1, and the phosphorylation levels of $\mathrm{I} \kappa \mathrm{B}-\alpha$ and $\mathrm{NF}-\kappa \mathrm{B}$ in the ischemic myocardial tissues were measured by western blot analysis (Fig. 5A). A significant increase in the levels of HMGB1, and the phosphorylation of $\mathrm{I} \kappa \mathrm{B}-\alpha$ at Ser32 and $\mathrm{NF}-\kappa \mathrm{B}$ at Ser536 was detected in the myocardial tissues following the induction of I/R (3.8-, 4.5- or 2.7-fold of the control levels, respectively); these increased levels were markedly reduced following treatment with osthole.

\section{Discussion}

Under myocardial ischemic conditions, the oxygen and nutrient demands of the heart tissues are decreased, and blood supply is also severely diminished (22). Therefore, the ensuing relative insufficiency of oxygen and ATP in turn induce a myriad of changes in cellular biomolecules and the activation of signaling pathways that in severe cases, result in cell demise $(23,24)$. With no effects on relieving the primary injury, re-establishment of the blood flow following prolonged ischemia aggravates the damage to the myocardium and eventually leads to structural and functional changes in patients (25). However, both the ischemic and reperfusion insults present opportunities for pharmacological agents to intervene and help salvage the injured heart tissues (26). In the present study, we found that osthole significantly reduced the infract volume induced by myocardial I/R injury, and also prevented the depletion of CK-MB isoenzyme and LDH enzymes in the ischemic heart tissues when administrated upon the initiation of I/R injury. In addition, treatment with osthole significantly preserved left ventricular function, as reflected by a significant increase in the indices of contraction $\left(+d p / d t_{\max }\right)$, relaxation $\left(-d p / d t_{\max }\right)$, LVSP and a decrease in LVEDP in the I/R insulted rat heart. All these data clearly demonstrate that osthole exertes protective effects against myocardial I/R injury in rats.

It is now well established that oxidative stress resulting from reactive oxygen species (ROS) and lipid peroxidation, which are generated in cardiac myocytes subjected to $I / R$ injury, plays a causative role in the development of ischemic 

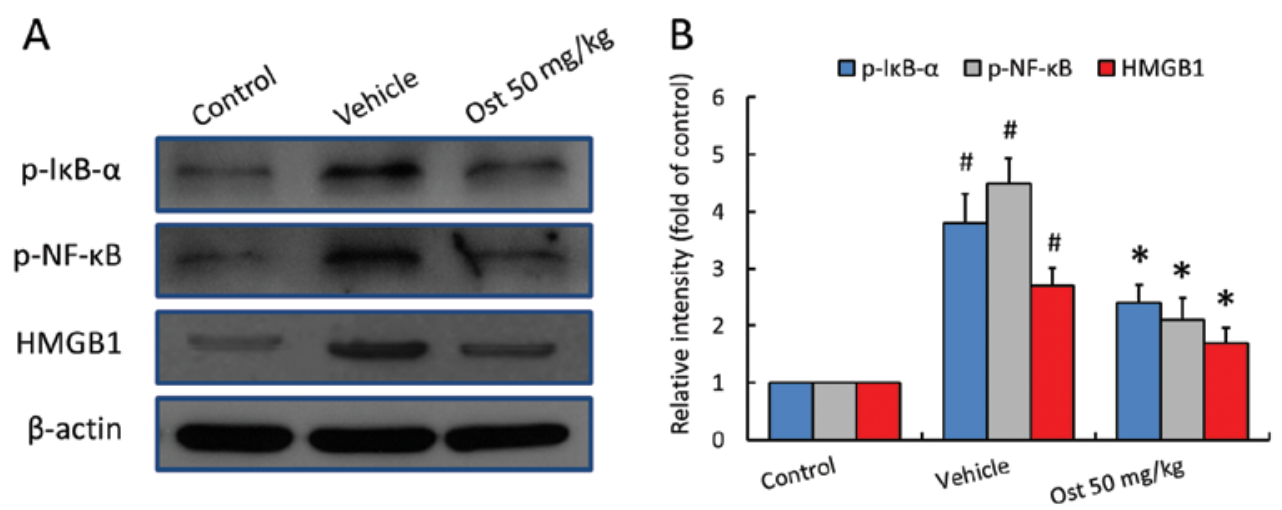

Figure 5. Osthole (Ost) decreases the expression of $\mathrm{p}-\mathrm{I \kappa B}-\alpha$, p-nuclear factor (NF)-кB and high-mobility group box protein 1 (HMGB1) following myocardial ischemia/reperfusion (I/R) injury. The rats were treated with dimethyl sulfoxide (DMSO) solution (vehicle) or $50 \mathrm{mg} / \mathrm{kg}$ osthole upon the initiation of myocardial I/R injury. (A) The expression of p-IкB- $\alpha, \mathrm{p}-\mathrm{NF}-\kappa \mathrm{B}$ and HMGB1 was detected by western blot analysis. (B) ImageJ software was then used to quantify the optical density of each band $24 \mathrm{~h}$ later. The data are presented as the means $\pm \mathrm{SD}$ from 6 experiments. ${ }^{*} \mathrm{P}<0.05$ vs. control group; ${ }^{*} \mathrm{P}<0.05$ vs. vehicle group.
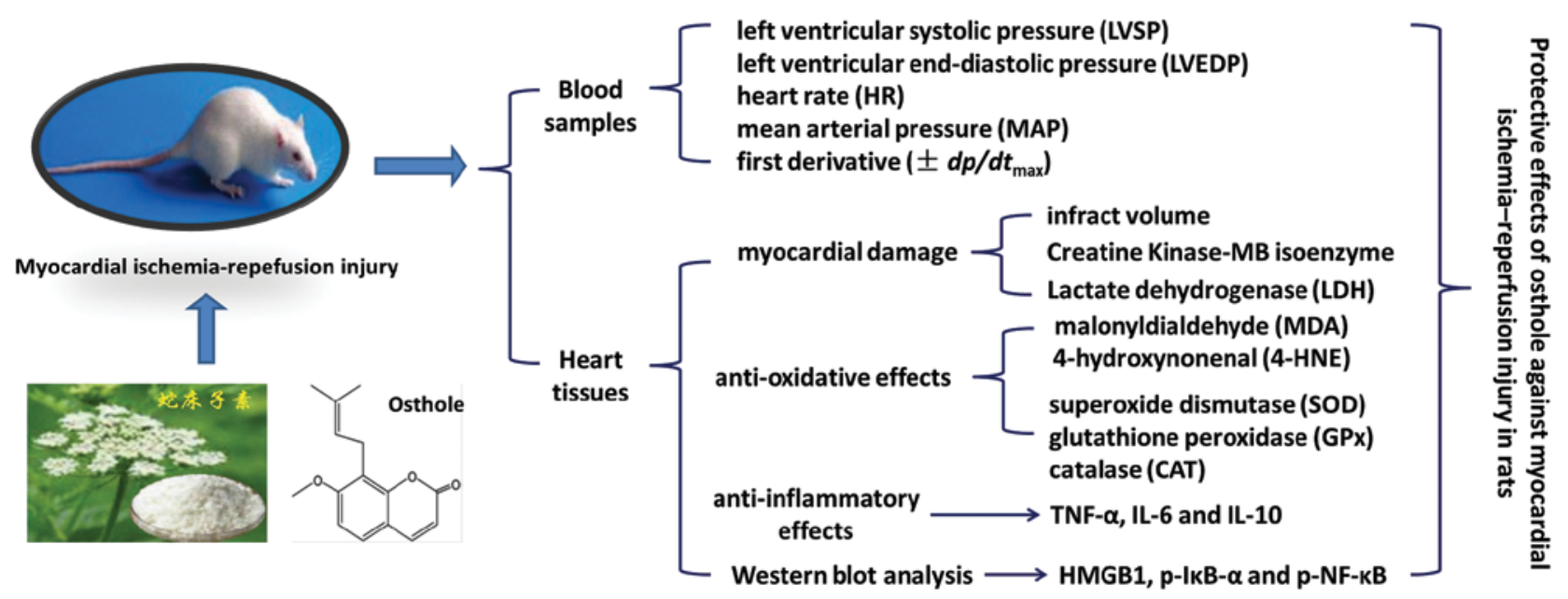

Figure 6. Diagram outlying the suggested mechanisms of action involved in osthole-induced cardioprotection.

heart disease and may contribute to the induction of cell death (27). Antioxidant enzymes are essential in keeping the physiological functions and play a fundamental role in coping with oxidative stress from endogenous or exogenous sources (28). Several antioxidant enzymes, such as SOD, GPx and CAT function synergistically to provide a line of defense against oxidative damage under a variety of stressful conditions, including I/R injury (29). Therefore, treatment with pharmacological agents with the ability to enhance the activities of antioxidant enzymes, or the enforced overexpression of antioxidant enzymes by using gene transfer approaches, represents a potential therapeutic option to attenuate tissue damage induced by I/R injury. For example, the combination of SOD and CAT gene delivery has achieved additive effects in preventing $\mathrm{I} / \mathrm{R}$-induced liver injury in mice, and herpes simplex virus (HSV)-mediated GPx overexpression in the striatum has been shown to reduce neuronal injury caused by cerebral I/R injury $(30,31)$. Furthermore, several natural products have been shown to exert protective effects against I/R injury by increasing the activities of antioxidant enzymes $(19,32,33)$. In the present study, osthole administration significantly increased the activities of SOD, GPx and CAT in the myocar- dial I/R-challenged rats in a dose-dependent manner, and suppressed the formation of the lipid peroxidation products, MDA and 4-HNE. These data demonstrate that treatment with osthole enhances the capacity of antioxidant enzymes and that this mechanism of action is attributed to its protective effects on oxidative stress-mediated injury in myocardial I/R-challenged animals.

Inflammatory processes play a crucial role in myocardial I/R injury, and myocardial cell damage is thought to be aggravated by the secondary intense inflammatory response initiated by the infiltration of leukocytes and the production of pro-inflammatory cytokines $(34,35)$. Numerous experimental studies have demonstrated that inflammatory mediators exacerbate myocardial damage not only during acute ischemic injury, but also in the ensuing reperfusion phase $(36,37)$. Treatments targeting cellular recruitment and the modulation of inflammatory cytokine secretion and activity have proven to be a potent therapeutic strategy for the reduction of myocardial I/R injury $(34,38)$. Inflammation-related cytokines are usually classified into pro- and anti-inflammatory mediators based on their ability to promote or suppress the activation of the immune system (39). In the present study, we demonstrated 
that ischemia and the ensuing reperfusion injury induced an increase in the plasma levels of pro-inflammatory mediators and a decrease in the expression of anti-inflammatory cytokines in the infarct area; these results are in accordance with those from previous studies (40-42). Treatment with osthole significantly decreased the levels of TNF- $\alpha$ and IL- 6 , while it increased IL-10 levels in the serum in a dose-dependent manner, as compared to the vehicle-treated animals. Therefore, we hypothesized that the protective effects of osthole against myocardial I/R injury may be attributed, at least in part, to the suppression of the inflammatory response via the inhibition of pro-inflammatory mediators and the promotion of antiinflammatory cytokines.

HMGB1, a nuclear non-histone DNA-binding protein, is highly conserved and can be found in the nuclei and cytoplasm of almost all cell types (43). It is a necessary and sufficient mediator of inflammation, and targeting HMGB1 with antibodies and specific antagonists has been shown to exert protective effects in several established inflammation-related disease models, including I/R-induced tissue injury (44). As shown in a previous study, HMGB1 expression increased following myocardial I/R injury as early as $30 \mathrm{~min}$ following ischemia, peaked at $12 \mathrm{~h}$, and remained significantly increased up to 7 days later (45). It has been demonstrated that HMGB1 is not only released in response to pro-inflammatory stimuli, but also induces the production of inflammatory mediators through multiple downstream signaling pathways, such as the receptor for advanced glycation endproducts (RAGE)-dependent sustained NF- $\mathrm{KB}$ activation $(46,47)$. Treatment with antiHMGB1 antibodies has been shown to prevent hepatic injury in response to ischemic insult-enhanced activation of the $\mathrm{NF}-\kappa \mathrm{B}$ pathway in vivo (48). Several agents have been demonstrated to have protective effects against myocardial I/R injury through the HMGB1-NF- $\kappa$ B pathway-dependent anti-inflammatory activities $(49,50)$. The results from the present study revealed that myocardial I/R injury induced significant increases in HMGB1 expression and the phosphorylation of $\mathrm{I} \kappa \mathrm{B}-\alpha$ and NF- $\kappa \mathrm{B}$; these increased levels were markedly reduced following treatment with osthole, with the analogous decreased expression levels of pro-inflammatory cytokines. Therefore, we hypothesized that the protective effects of osthole may be attributed, at least part, to the suppression of inflammatory cascades through an HMGB1-dependent NF- $\mathrm{B}$ signaling pathway.

In conclusion, in this study, we determined that osthole reduces myocardial injury and improves functional recovery following myocardial I/R injury (Fig. 6). Osthole significantly increased the activities of SOD, GPx and CAT in a dosedependent manner, and suppressed the formation of the lipid peroxidation products, MDA and 4-HNE, in the injured heart tissues. These effects of osthole correlated with the decrease in the expression of pro-inflammatory factors, the increase in the expression of anti-inflammatory cytokines in the serum, as well as with the inhibition of the expression of HMGB1 and phosphorylated $\mathrm{I} \kappa \mathrm{B}-\alpha$ and $\mathrm{NF}-\kappa \mathrm{B}$ proteins. These protective effects of osthole against myocardial I/R injury appeared to be mainly mediated by its anti-inflammatory and antioxidant activities. Taken together, these data suggest that osthole may prove to be an important therapeutic agent for limiting the severity and functional deficits associated with myocardial I/R injury.

\section{Acknowledgements}

This study was financially supported by the National Natural Science Foundation of China (no.81200633) and the Guangzhou Science and Technology Plan Project (no. 2011J4100021).

\section{References}

1. Thom T, Haase N, Rosamond $\mathrm{W}$, et al: Heart disease and stroke statistics - 2006 update: a report from the American Heart Association Statistics Committee and Stroke Statistics Subcommittee. Circulation 113: e85-e151, 2006.

2. Lloyd-Jones D, Adams RJ, Brown TM, et al: Heart disease and stroke statistics - 2010 update: a report from the American Heart Association. Circulation 121: e46-e215, 2010.

3. Renda $\mathrm{G}$ and de Caterina R: Impact of antiplatelet therapy in heart disease. Adv Cardiol 47: 5-19, 2012.

4. Gnecchi M, Danieli P and Cervio E: Mesenchymal stem cell therapy for heart disease. Vascul Pharmacol 57: 48-55, 2012.

5. Songco AV and Brener SJ: Initial strategy of revascularization versus optimal medical therapy for improving outcomes in ischemic heart disease: a review of the literature. Curr Cardiol Rep 14: 397-407, 2012.

6. Ji X, Tan BK, Zhu YC, Linz W and Zhu YZ: Comparison of cardioprotective effects using ramipril and DanShen for the treatment of acute myocardial infarction in rats. Life Sci 73: 1413-1426, 2003.

7. Bolli R, Becker L, Gross G, Mentzer R Jr, Balshaw D and Lathrop DA: Myocardial protection at a crossroads: the need for translation into clinical therapy. Circ Res 95: 125-134, 2004.

8. Sun J, Tan BK, Huang SH, Whiteman M and Zhu YZ: Effects of natural products on ischemic heart diseases and cardiovascular system. Acta Pharmacol Sin 23: 1142-1151, 2002.

9. $\mathrm{He} \mathrm{H}, \mathrm{Xu} \mathrm{J}, \mathrm{Xu} \mathrm{Y}$, et al: Cardioprotective effects of saponins from Panax japonicus on acute myocardial ischemia against oxidative stress-triggered damage and cardiac cell death in rats. J Ethnopharmacol 140: 73-82, 2012.

10. Ko FN, Wu TS, Liou MJ, Huang TF and Teng CM: Vasorelaxation of rat thoracic aorta caused by osthole isolated from Angelica pubescens. Eur J Pharmacol 219: 29-34, 1992.

11. Huang RL, Chen CC, Huang YL, et al: Osthole increases glycosylation of hepatitis B surface antigen and suppresses the secretion of hepatitis B virus in vitro. Hepatology 24: 508-515, 1996.

12. Liu JH, Zschocke S, Reininger E and Bauer R: Inhibitory effects of Angelica pubescens f. biserrata on 5-lipoxygenase and cyclooxygenase. Planta Med 64: 525-529, 1998.

13. Xu XM, Zhang Y, Qu D, Feng XW, Chen Y and Zhao L: Osthole suppresses migration and invasion of A549 human lung cancer cells through inhibition of matrix metalloproteinase- 2 and matrix metallopeptidase-9 in vitro. Mol Med Rep 6: 1018-1022, 2012.

14. Lin VC, Chou CH, Lin YC, et al: Osthole suppresses fatty acid synthase expression in HER2-overexpressing breast cancer cells through modulating Akt/mTOR pathway. J Agric Food Chem 58: 4786-4793, 2010.

15. Okamoto T, Kawasaki $\mathrm{T}$ and Hino $\mathrm{O}$ : Osthole prevents anti-Fas antibody-induced hepatitis in mice by affecting the caspase-3-mediated apoptotic pathway. Biochem Pharmacol 65: 677-681, 2003.

16. Li XX, Hara I and Matsumiya T: Effects of osthole on postmenopausal osteoporosis using ovariectomized rats; comparison to the effects of estradiol. Biol Pharm Bull 25: 738-742, 2002.

17. Matsuda H, Tomohiro N, Ido Y and Kubo M: Anti-allergic effects of Cnidii Monnieri Fructus (dried fruits of Cnidium monnieri) and its major component, osthol. Biol Pharm Bull 25: 809-812, 2002.

18. Chao X, Zhou J, Chen T, et al: Neuroprotective effect of osthole against acute ischemic stroke on middle cerebral ischemia occlusion in rats. Brain Res 1363: 206-211, 2010.

19. Chen T, Liu W, Chao X, et al: Neuroprotective effect of osthole against oxygen and glucose deprivation in rat cortical neurons: involvement of mitogen-activated protein kinase pathway. Neuroscience 183: 203-211, 2011.

20. Lee YS, Kang YJ, Kim HJ, et al: Higenamine reduces apoptotic cell death by induction of heme oxygenase- 1 in rat myocardial ischemia-reperfusion injury. Apoptosis 11: 1091-1100, 2006. 
21. Hwa JS, Jin YC, Lee YS, et al: 2-methoxycinnamaldehyde from Cinnamomum cassia reduces rat myocardial ischemia and reperfusion injury in vivo due to HO-1 induction. J Ethnopharmacol 139 605-615, 2012

22. Raedschelders K, Ansley DM and Chen DD: The cellular and molecular origin of reactive oxygen species generation during myocardial ischemia and reperfusion. Pharmacol Ther 133: 230-255, 2012.

23. Sanada S, Komuro I and Kitakaze M: Pathophysiology of myocardial reperfusion injury: preconditioning, postconditioning, and translational aspects of protective measures. Am J Physiol Heart Circ Physiol 301: H1723-H1741, 2011.

24. Garcia-Dorado D, Agullo L, Sartorio CL and Ruiz-Meana M: Myocardial protection against reperfusion injury: the cGMP pathway. Thromb Haemost 101: 635-642, 2009.

25. Bell RM and Yellon DM: There is more to life than revascularization: therapeutic targeting of myocardial ischemia/reperfusion injury. Cardiovasc Ther 29: e67-e79, 2011.

26. Akhlaghi M and Bandy B: Mechanisms of flavonoid protection against myocardial ischemia-reperfusion injury. $\mathrm{J}$ Mol Cell Cardiol 46: 309-317, 2009.

27. Rakotovao A, Berthonneche C, Guiraud A, et al: Ethanol, wine, and experimental cardioprotection in ischemia/reperfusion: role of the prooxidant/antioxidant balance. Antioxid Redox Signal 6 : 431-438, 2004.

28. Wu J, Hecker JG and Chiamvimonvat N: Antioxidant enzyme gene transfer for ischemic diseases. Adv Drug Deliv Rev 61: 351-363, 2009.

29. Limon-Pacheco $\mathrm{J}$ and Gonsebatt ME: The role of antioxidants and antioxidant-related enzymes in protective responses to environmentally induced oxidative stress. Mutat Res 674: 137-147, 2009.

30. He SQ, Zhang YH, Venugopal SK, et al: Delivery of antioxidative enzyme genes protects against ischemia/reperfusion-induced liver injury in mice. Liver Transpl 12: 1869-1879, 2006.

31. Hoehn B, Yenari MA, Sapolsky RM and Steinberg GK: Glutathione peroxidase overexpression inhibits cytochrome C release and proapoptotic mediators to protect neurons from experimental stroke. Stroke 34: 2489-2494, 2003.

32. Zhu JW, Chen T, Guan J, Liu WB and Liu J: Neuroprotective effects of allicin on spinal cord ischemia-reperfusion injury via improvement of mitochondrial function in rabbits. Neurochem Int 61: 640-648, 2012.

33. Ye R, Yang Q, Kong X, et al: Ginsenoside Rd attenuates early oxidative damage and sequential inflammatory response after transient focal ischemia in rats. Neurochem Int 58: 391-398, 2011.

34. Frangogiannis NG, Smith CW and Entman ML: The inflammatory response in myocardial infarction. Cardiovasc Res 53: 31-47, 2002.
35. Yellon DM and Hausenloy DJ: Myocardial reperfusion injury. N Engl J Med 357: 1121-1135, 2007.

36. Jordan JE, Zhao ZQ and Vinten-Johansen J: The role of neutrophils in myocardial ischemia-reperfusion injury. Cardiovasc Res 43: 860-878, 1999.

37. Steffens S, Montecucco F and Mach F: The inflammatory response as a target to reduce myocardial ischaemia and reperfusion injury. Thromb Haemost 102: 240-247, 2009.

38. Frangogiannis NG: Chemokines in ischemia and reperfusion. Thromb Haemost 97: 738-747, 2007.

39. Chen T, Liu W, Chao X, et al: Salvianolic acid B attenuates brain damage and inflammation after traumatic brain injury in mice. Brain Res Bull 84: 163-168, 2011.

40. Chandrasekar B and Freeman GL: Induction of nuclear factor kappaB and activation protein 1 in postischemic myocardium. FEBS Lett 401: 30-34, 1997.

41. Chandrasekar B, Colston JT and Freeman GL: Induction of proinflammatory cytokine and antioxidant enzyme gene expression following brief myocardial ischaemia. Clin Exp Immunol 108: 346-351, 1997.

42. Li C, Gao Y, Xing Y, Zhu H, Shen J and Tian J: Fucoidan, a sulfated polysaccharide from brown algae, against myocardial ischemia-reperfusion injury in rats via regulating the inflammation response. Food Chem Toxicol 49: 2090-2095, 2011.

43. Lotze MT and Tracey KJ: High-mobility group box 1 protein (HMGB1): nuclear weapon in the immune arsenal. Nat Rev Immunol 5: 331-342, 2005.

44. Yang $\mathrm{H}$ and Tracey $\mathrm{KJ}$ : Targeting HMGB1 in inflammation. Biochim Biophys Acta 1799: 149-156, 2010.

45. Andrassy M, Volz HC, Igwe JC, et al: High-mobility group box-1 in ischemia-reperfusion injury of the heart. Circulation 117: 3216-3226, 2008.

46. Schmidt AM, Yan SD, Yan SF and Stern DM: The multiligand receptor RAGE as a progression factor amplifying immune and inflammatory responses. J Clin Invest 108: 949-955, 2001.

47. Volz HC, Kaya Z, Katus HA and Andrassy M: The role of HMGB1/RAGE in inflammatory cardiomyopathy. Semin Thromb Hemost 36: 185-194, 2010.

48. Tsung A, Sahai R, Tanaka H, et al: The nuclear factor HMGB1 mediates hepatic injury after murine liver ischemia-reperfusion. J Exp Med 201: 1135-1143, 2005.

49. Jiang WL, Zhang SP, Zhu HB and Hou J: Cardioprotection of Asperosaponin $\mathrm{X}$ on experimental myocardial ischemia injury. Int J Cardiol 155: 430-436, 2012.

50. Kang ZC, Jiang WL, Xu Y, Zhu HB and Hou J: Cardioprotection with 8-O-acetyl shanzhiside methylester on experimental myocardial ischemia injury. Eur J Pharm Sci 47: 124-130, 2012. 